\title{
Dynamic tensile tests on ferritic and austenitic steels with improved testing and measuring technique
}

K. Kussmaul and M. Schuele

Staatliche Materialprüfungsanstalt (MPA), Universität Stuttgart, Pfaffenwaldring 32, 70569 Stuttgart, Germany

\begin{abstract}
Résumé: $\quad$ - Pour une analyse des structures soumises aux charges dynamiques à l'aide de la méthode des éléments finis un modèle constitutif dynamique est nécessaire pour obtenir des résultats fiables. Pour cette raison des essais dynamiques de traction ont été faits aux différentes vitesses avec l'acier à gros grains $20 \mathrm{MnMoNi} 55$ (A $508 \mathrm{Cl}$. 3) et l'acier austénitique $\mathrm{X} 6 \mathrm{CrNi} 1811$. Des éprouvettes rondes et lisses de différentes géométries ont été utilisées. Les déplacements à l'extrémité basse de l'éprouvette ainsi que la force et l'extension ont été mesurés. L'évenement entier de l'impact pendant les essais dynamiques de traction à l'aide de la $33 \mathrm{MJ}$ machine d'impact de rotation est simulé en utilisant le code des éléments finis DYNA3D. On a obtenu des informations concernant les conditions de charge et observé la distribution des contraintes, l'extension et la vitesse de l'extension le long de la jauge de contraintes pendant l'essai. De cette manière la technique de mesurer les contraintes et l'extension pouvait être améliorée. Finalement le comportement dynamique contraintes/extension de l'acier ferritique et austénitique est discuté.
\end{abstract}

\begin{abstract}
For analysing dynamically loaded structures by means of the finite element method a dynamic constitutive material model is necessary to obtain reliable results. For this purpose dynamic tensile tests were performed with the fine grained steel $20 \mathrm{MnMoNi} 55$ (A $508 \mathrm{Cl}$. 3) and the austenitic steel $\mathrm{X} 6 \mathrm{CrNi} 1811^{\circ}$ at different velocities. Smooth round bar specimens of different geometries were used. Displacement at the lower end of the specimen as well as force and strain were measured. The whole impact event taking place during dynamic tensile tests on a $33 \mathrm{MJ}$-rotating disk impact machine is simulated by means of the explicit finite element code DYNA3D. Information on the loading conditions during the test could be obtained and stress, strain respectively strain rate distribution along the gauge length were observed. Thus the measuring technique of stress and strain could be improved. Finally the dynamic stress-strain behaviour of the ferritic and austenitic steel is discussed.
\end{abstract}

\section{INTRODUCTION}

Higher loading rates are found in many technical fields such as traffic, production and energy techniques. For dynamic numerical safety analyses, it is a widely recognised fact that, besides dynamic material properties, there is an increasing demand for complete stress-strain curves as a function of strain rate and that the dynamic tensile test is the most appropriate tool to provide information on that material property. Among the testing devices for intermediate loading rates up to $1000 \mathrm{~s}^{-1}$, like servo-hydraulic high speed tensile testing machines and pendulum impact testers, counts also the rotating disk impact machine, Figure 1 , which provides velocities up to $150 \mathrm{~m} / \mathrm{s}$. For strain rates $\dot{\varepsilon}>1 \mathrm{~s}^{-1}$ the load cannot be measured by 


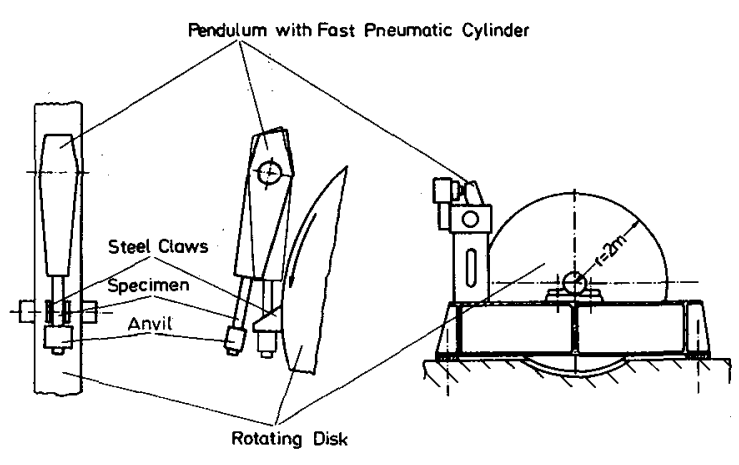

Figure 1: $33 \mathrm{MJ}$ rotating disk impact machine

standard devices such as strain gauge instrumented load cells or piezoelectric load washers. The load must be determined on dynamometer sections (Figure 2). Reaching strain rates of $\dot{\varepsilon}>500 \mathrm{~s}^{-1}$, the stress-strain curve, especially the upper yield stress, cannot be derived reliably due to ringing in the load signals. To analyse this problem the whole impact event taking place during a dynamic tensile test with a smooth round bar specimen in the rotating disk impact machine is simulated. The finite element model is validated by means of comparison with experimental results. Additional information about the loading conditions could be obtained. A technique to obtain reliable material properties despite oscillations in the load signals will be described.

\section{EXPERIMENTAL SET-UP AND FINITE ELEMENT MODEL}

The rotating disk impact machine is equipped with fixed steel claws, Figure 1 . When the specified testing conditions are established, the specimen and the anvil are slewed into the path of the claws by a fast acting pneumatic cylinder. The impact of the steel claws is damped by aluminium cylinders. These damping elements have a strong influence on the time the anvil needs for acceleration to the circumferential velocity of the rotating disk. The dampers are fixed on the anvil to try and avoid any asymmetric impact and bending of the specimen.

The tests were performed with smooth round bar specimens, Figure 2, made of the fine-grained structural steel $20 \mathrm{MnMoNi} 55$ (yield strength $R_{\mathrm{eL}}=524 \mathrm{MPa}$, ultimate tensile strength $\mathrm{R}_{\mathrm{m}}=656 \mathrm{MPa}$, elongation at fracture $\mathrm{A}_{5}=25 \%$ at ambient temperature) and the austenitic steel $\mathrm{X} 6 \mathrm{CrNi} 1811$ (proof strength $R_{p 0,2}=256 \mathrm{MPa}$, ultimate tensile strength $R_{\mathrm{m}}=586 \mathrm{MPa}$, elongation at fracture $A_{5}=61 \%$ at ambient temperature). In order to compensate bending effects during the dynamic test, two standard type strain gauges with small gauge length were attached on opposite faces of each dynamometer section. The limiting frequency of the strain gauge amplifier was $500 \mathrm{kHz}$ and the maximum sample rate of the transient recorder was $2 \mathrm{MHz}$. For materials with a distinct yield point like the steel $20 \mathrm{MnMoNi} 55$, the strain gauges can be calibrated quasi-statically prior to the dynamic test at the test temperature if Young's Modulus is unknown. The strain signal, monitored during the dynamic test, is converted into the load signal by applying the calibration factor. For test materials without distinct yield point like the steel $\mathrm{X} 6 \mathrm{CrNi} 1811$ a calibration procedure is not practical due to plastic deformation. Here Young's Modulus of the material of the dynamometer sections is used to calculate the calibration factor. In the case of the austenitic steel for the dynamometer sections, a ferritic steel with a well-known Young's Modulus was welded onto the gauge length by electron beam.

Post yield strain gauges were attached to the gauge length of the smooth round bar specimens for strain measurement. An opto-electronic sensor / $1 /$ illuminates and measures the reflected light of a bar code applied at one side of the anvil. The displacement and velocities of the anvil can be deduced from the signal of the sensor. The impact velocities of the tests varied between $3 \mathrm{~m} / \mathrm{s}$ and $15 \mathrm{~m} / \mathrm{s}$. 


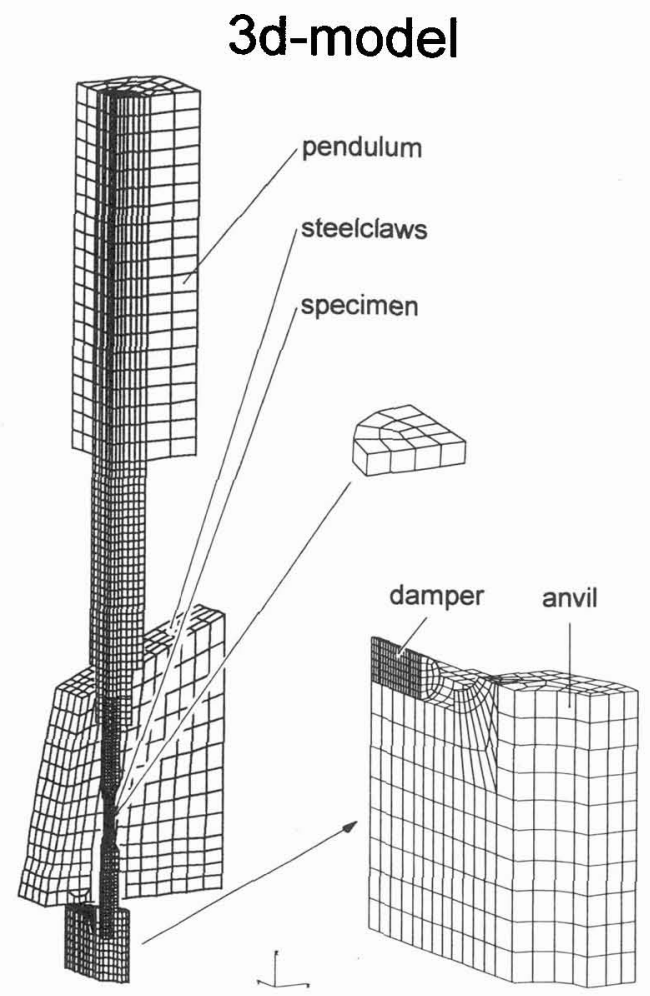

Figure 3: Finite element 3d-idealisation

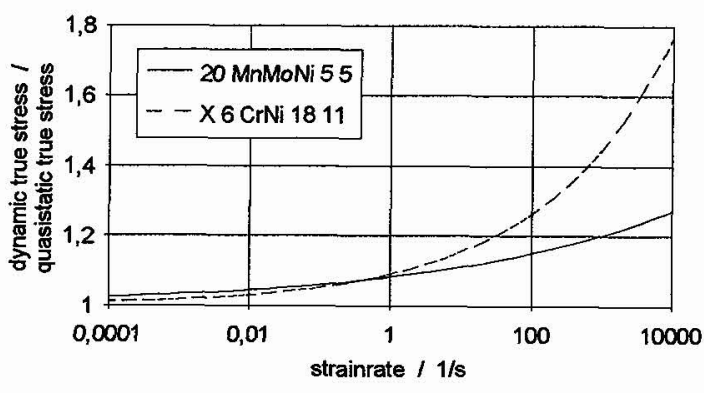

Figure 4: Strain rate dependence

The finite element model for the simulation of the impact event, Figure 3 , consists of all parts that are relevant for the transmission of force onto the specimen. Hexahedron elements are much more efficient and were used for the whole model consisting of about 4330 elements and about 6460 nodes. Except the steel claws, only a quarter of the model is meshed which is due to symmetry. The material behaviour of the anvil, the steel claws and the pendulum is assumed to be elastic. For the specimen and the damper an elastic-plastic material model was used. The strain rate dependence, Figure 4 , given in a point by point representation was considered for the specimen only, because of the low sensitivity of aluminium on strain rate effects. The finite element code DYNA3D $/ 2 /$ on a CRAY 2 computer was used to perform the calculations. In order to simulate a dynamic event with a large model, the use of first order isoparametric elements with a vectorized explicit time integration scheme realised in DYNA3D $/ 3 /$ is advantageous. An hourglass control according to Flanagan and Belytschko /4/ was used. Although the minimum time step of the calculations was $\sim 9 \mathrm{~ns}$, the CPU-time of the simulations ranged from $500 \mathrm{~s}$ up to $5000 \mathrm{~s}$ depending on the time the experimental test needed. An interface definition with friction was used to model the interfaces between steel claws and dampers respectively between dampers and anvil. The screws of the smooth round bar specimen were modelled by spotwelds which couple the displacement of two nodes only in the load direction. On the top of the pendulum nonreflecting boundaries were used because only the lower part of the pendulum was modelled.

\section{EXPERIMENTAL RESULTS}

The experimental and numerical results were in good agreement. Figure 5 shows the measured and calculated velocity of the anvil for a tensile test with a smooth round bar specimen. The material was the steel $20 \mathrm{MnMoNi} 55$, the gauge length was $30 \mathrm{~mm}$ and the circumferential velocity of the disk was $7.5 \mathrm{~m} / \mathrm{s}$. The oscillations in velocity depend on the geometry and have the same frequency for all impact velocities, that means they are only visible at higher velocities. The rise time of the anvil velocity, which amounts to $75 \mu \mathrm{s}$, is dependent on the mass of the anvil, the geometry of the

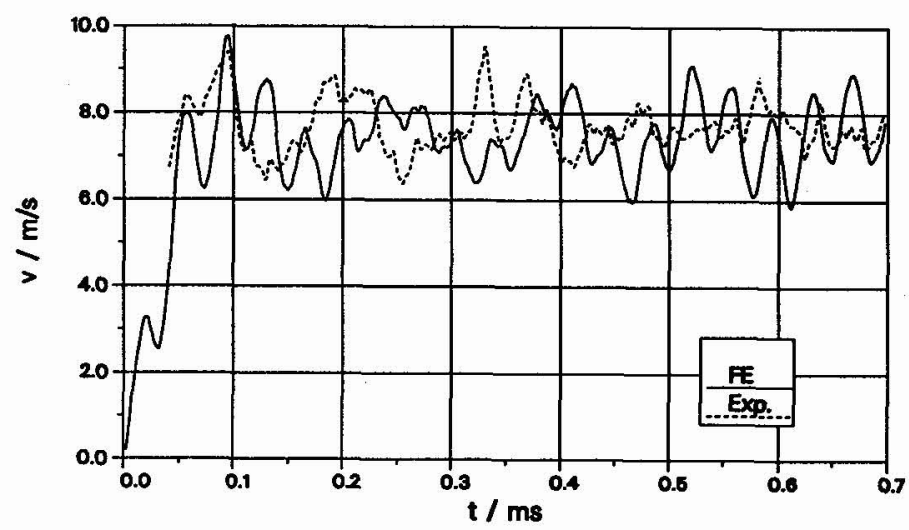

Figure 5: Velocity of the anvil for a tensile test with $7.5 \mathrm{~m} / \mathrm{s}$ 
damping element, as well as the resistance of the specimen and is nearly independent of the circumferential velocity of the disk. To minimise the mass which has to be accelerated during the test, the anvil was made of Titanium.

Figure 6 shows the strain rate measured by the post yield strain gauge and calculated by finite element method for the same test. It is remarkable that the numerical and experimental results show the same oscillations. Since the elevation of the upper yield stress is not described in the material model, the numerical results are different from the experimental ones in the range of the onset of plastic flow. The determined stress-time curve at the upper dynamometer section is compared with the calculated stresstime curve in Figure 7. Even the stress-time curve of the calculation shows the oscillations. The numerical results for the steel $20 \mathrm{MnMoNi} 55$ show an upper yield stress in the range of the onset of plastic deformation, although this is not included in the material model. The value of upper yield stress obtained depends upon the size of the oscillations.

The amplitude $\sigma_{\mathrm{A}}$ of the oscillations can be ascertained by neglecting damping of the oscillations in the region of the lower yield stress, Figure 8. To obtain a reliable upper yield stress, this amplitude must be subtracted from the determined value. To investigate whether this procedure is suitable for the determination of the dynamic upper yield stress, a calculation was carried out with a theoretical upper yield stress in the material model. The difference between $R_{e H, d}$ and $R_{e L, d}$ of about $172 \mathrm{MPa}$ was divided by the factor of stress increase 1.182 of the true stress-true strain curve for the obtained strain rate. The result of $146 \mathrm{MPa}$ was added to the yield point of the quasi-static true stresstrue strain curve used for the dynamic material model. The comparison of the experimental and numerical results at the upper dynamometer section in Figure 9 shows a good agreement in the range of the upper yield stress. The presence of an upper yield point leads to a higher amplitude of the

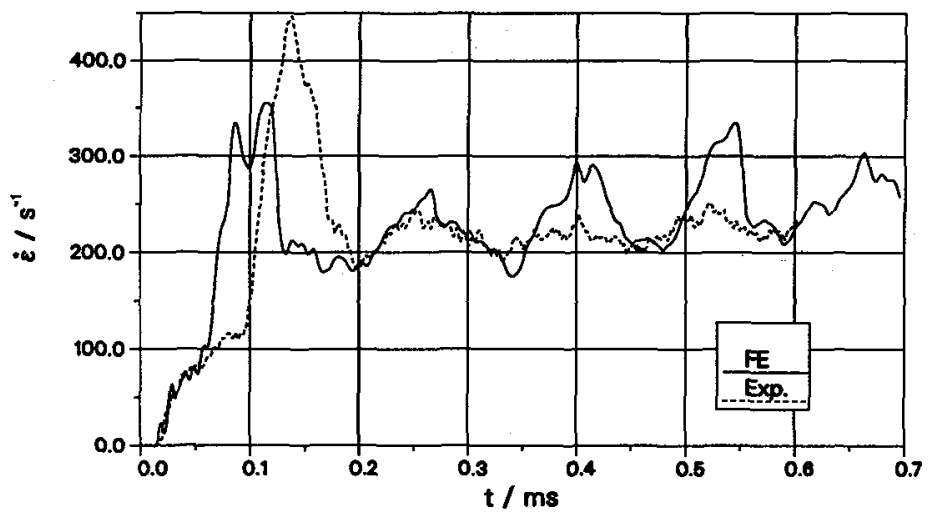

Figure 6: Strain rate for a tensile test with $7.5 \mathrm{~m} / \mathrm{s}$

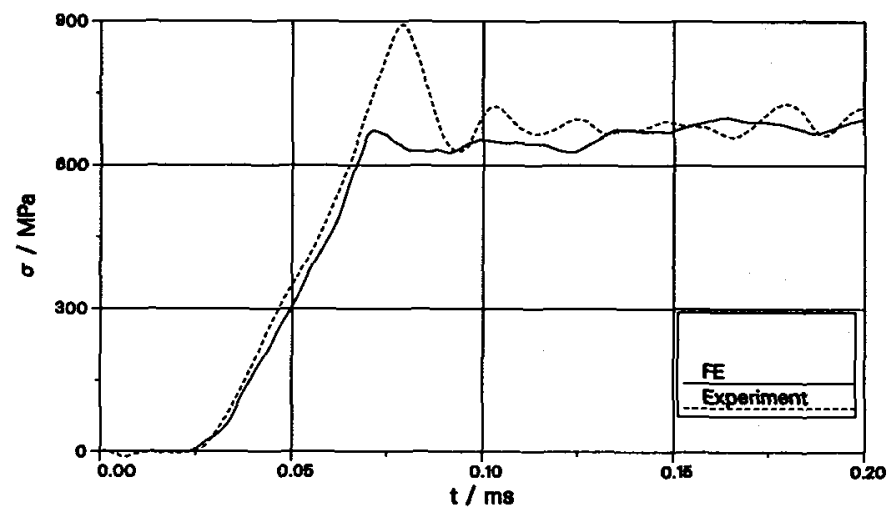

Figure 7: Stress-time curve for a tensile test with $7.5 \mathrm{~m} / \mathrm{s}$

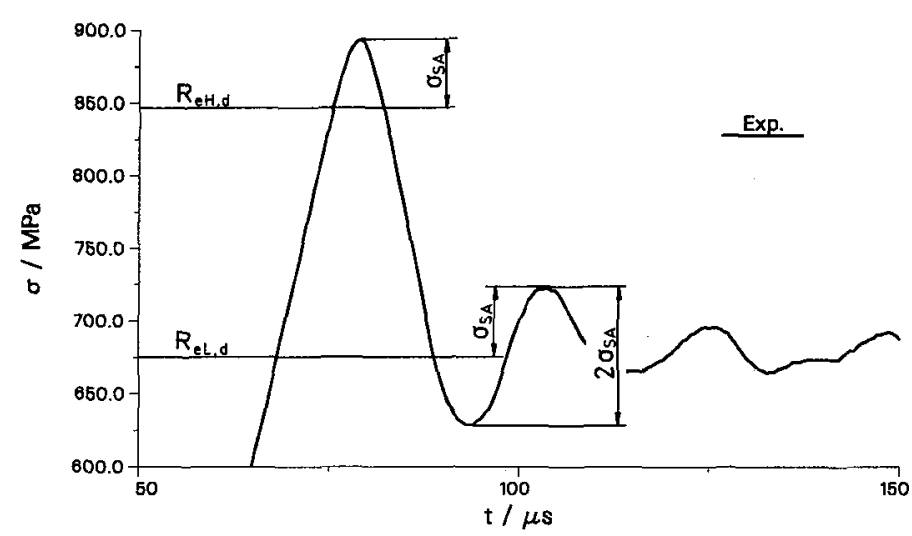

Figure 8: Determination of the dynamic upper yield strength $\mathrm{R}_{\mathrm{eH}, \mathrm{d}}$ 


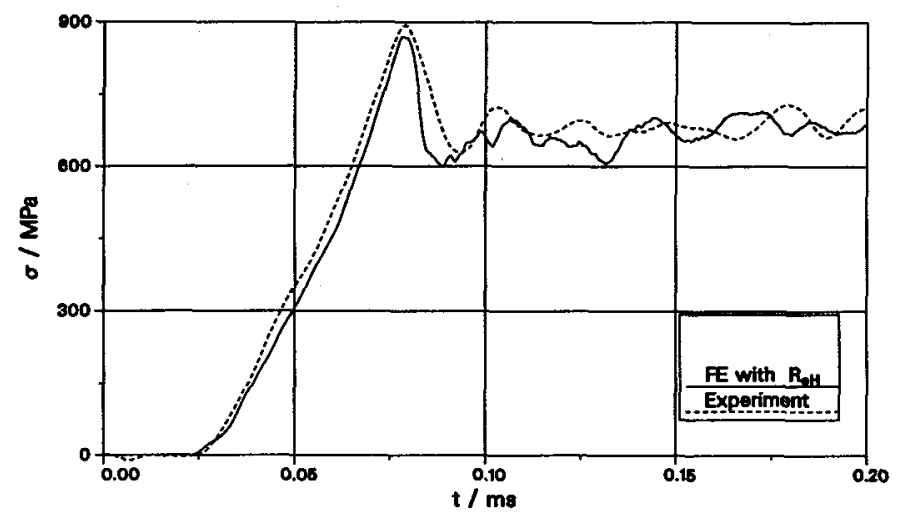

Figure 9: Stress-time curve for a tensile test with $7.5 \mathrm{~m} / \mathrm{s}$ and $\mathrm{R}_{\mathrm{eH}}$

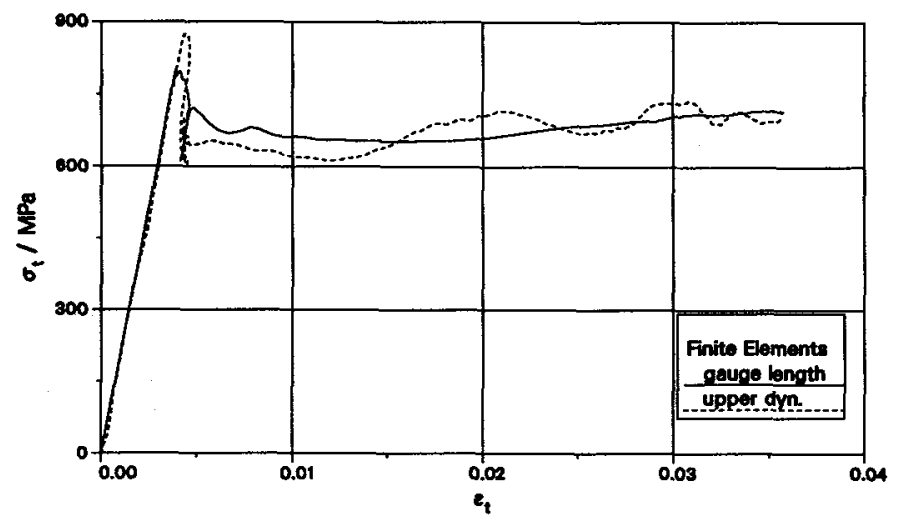

Figure 10: Calculated true stress-true strain curve

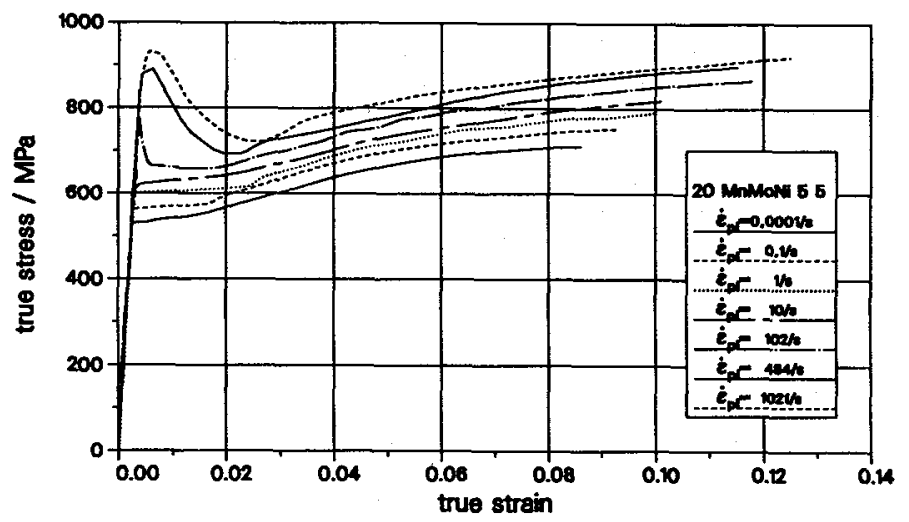

Figure 11: Dynamic stress-strain curves for $20 \mathrm{MnMoNi} 55$ oscillations. By comparing the calculated true stress-true strain curves derived from the upper dynamometer section and the real stress in the gauge length, Figure 10 , the difference at the upper yield stress is visible. As concerns the further course of the stress-time curve filtering can help to obtain reliable stress-strain curves especially for the lower yield point and the point of ultimate tensile strength. The stress-strain curve of the upper dynamometer section describes the material behaviour more accurately. At the beginning of the test part of the force obtained at the lower dynamometer section is caused by mass acceleration leading to an increase of stress in the elastic region. Furthermore, the higher elastic deformation in the lower dynamometer section leads to a higher amplitude of the oscillations.

The analysis of the axial stresses over the gauge length of the specimen showed a homogeneous stress distribution after the onset of plastic flow. Wave propagation and reflection effects can be observed only in the elastic part of the loading history. In the elastically deformed dynamometer sections wave propagation and reflection could be observed during the whole test leading to the oscillations in the measured signals. Especially after the onset of an upper yield point the amplitude of the oscillations is higher.

Figure 11 shows the true stress-true strain curves for various strain rates of the ferritic steel $20 \mathrm{MnMoNi} 55$. It is obvious that the curves shift to higher stresses if the strain rate is increased. The upper yield stress increases much more. For accurate dynamic finite-element calculations, a material model with true stresstrue strain curves for different strain rates has to be used.

In the case of the austenitic steel X6 CrNi 1811 a diminution of the work hardening occurs. The calculated temperature increase of the material in the gauge length caused by plastic deformation is about $70^{\circ} \mathrm{C}$ to $90^{\circ} \mathrm{C}$. For that reason thermal softening alone cannot explain the described effect. This strain rate dependency is not 
considered in any of the dynamic material models of DYNA3D and leads to a divergence of the stresstime curves of the FE-calculation and the experiment, Figure 12. The velocity in this test was $10 \mathrm{~m} / \mathrm{s}$ and the specimen's gauge length was $10 \mathrm{~mm}$. The strain rate dependence of the true stress-true strain curves, Figure 4, was calculated in the range of 0.01 to 0.05 strain, because there is no constant factor over the whole amount of strain. For this reason the stress-time curve in Figure 12 shows a good agreement up to strains of about 0.1 . The austenitic steel has no distinct yield point. That leads to a smaller amplitude of the oscillations caused by the force measuring system. There is no upper yield point if the amplitude of the oscillations has almost the same value at the yield point and in the plastic region.

Figure 13 shows the true stress-true strain curves in dependence of the strain rate for the austenitic steel $\mathrm{X} 6 \mathrm{CrNi} 1811$. Increasing strain rate leads to a diminution of the slope in the plastic region.

\section{CONCLUSION}

A technique to measure the force for strain rates up to $\dot{\varepsilon} \approx 1000 \mathrm{~s}^{-1}$ is described. Oscillations increase the obtained upper yield stress by reaching strain rates of $\dot{\varepsilon}>500 \mathrm{~s}^{-1}$. The upper yield stress can be Figure 13: Dynamic stress-strain curves for the steel X6 CrNi 1811 calculated by subtracting the amplitude of the oscillations. This was checked by finite-element calculations and provides reliable material properties despite oscillations in the load signals. The quasi-static true stress-true strain curve of the dynamic material model has to be modified in the range of the yield point for that strain rate because of the higher increase of the upper yield stress by increasing strain rate for the ferritic steel $20 \mathrm{MnMoNi} 55$. The calculations validated the method for determining the dynamic upper yield stress. The austenitic steel shows a strain rate dependent diminution of the work hardening of the stress-strain curve that cannot be explained only by a thermal softening effect. For a more accurate finite-element calculation a material model with true stress-true strain curves for different strain rates should be used.

\section{REFERENCES}

/1/ Kussmaul, K., Demler, T., Klenk, A., Int. Phys. Conf. Ser. No 102: Sess. 4

12/ Hallquist, J. O., Lawrence Livermore Nat. Lab., Rept. UCID-19592 1986

/3/ Hallquist, J. O., Lawrence Livermore Nat. Lab., Rept. UCID-19401 1982

/4/ Flanagan, D. P., Belytschko, T., Int. J. Num. Meth. Eng. 17, 1981, pp. 673-706 